\title{
器 \\ Avaliação da qualidade microbiológica de filés de tilápia-do-nilo (Oreochromis niloticus) e do gelo e a interação dos fatores após armazenagem
}

\author{
[Microbiological quality of tilapia-do-nilo (Oreochromis niloticus) fillets and ice and the \\ interaction of factors after storage]
}

\section{"Artigo Científico/Scientific Article"}

\author{
Camila Maria Coutinho Moura*, Juliana de Abreu Costa, Aline Martins de Sousa, \\ José Humberto Santos Filho, Rafael Gomes Abreu Bacelar, Julliet Teixeira de Oliveira Santos, \\ Maria Christina Sanches Muratori
}

Departamento de Morfofisiologia Veterinária, Universidade Federal do Piauí, Teresina - PI, Brasil.

*Autor para correspondência/Corresponding author: E-mail: cahmila@live.com

\begin{abstract}
Resumo
O presente trabalho objetivou analisar a qualidade microbiológica do filé de tilápia (Oreochromis niloticus) e do gelo comercializado no Mercado do Peixe em Teresina, PI e avaliar a interação de contaminação entre as partes analisadas. Foram coletadas 24 amostras de peixes e três amostras de gelo no Mercado do Peixe em Teresina, PI, os peixes foram transportadas em caixas isotérmicas para o laboratório onde foram filetados. A primeira etapa consistia nas análises microbiológicas do filé e do gelo para contagem de bactérias heterotróficas mesófilas e psicrotróficas e enumeração de coliformes termotolerantes e totais. A outra parte do filé foi acondicionada em caixa isotérmica com a amostra de gelo para estocagem por oito horas, período este que corresponde ao período de comercialização no mercado do peixe. Decorrido esse tempo também eram realizadas as mesmas análises microbiológicas. Pode-se verificar que as amostras de gelo que foram analisadas imediatamente após chegar ao laboratório não apresentavam contaminação microbiológica. Entretanto, as amostras de filé possuíam índices semelhantes de contaminação bacteriana antes e após estocagem. O gelo que após ser utilizado para o acondicionamento do filé apresentou quantidade de bactérias heterotróficas mesófilas e psicrófilas semelhantes aos filés.
\end{abstract}

Palavras-chave: bactérias heterotróficas; coliformes; psicrotróficas.

\begin{abstract}
The present work aimed to analyze the microbiological conditions of the fillet of tilapia (Oreochromis niloticus) and ice commercialized at the Fish Market in Teresina, PI and to evaluate the interaction of contamination between the analyzed parts. Twenty-four fish samples and three ice samples were collected at the Fish Market in Teresina, PI; the fish were transported in isothermal boxes to the laboratory where they were filleted. The first stage consisted of the microbiological analyses of fillet and ice for the counting of mesophilic and psychrotrophic heterotrophic bacteria and enumeration of thermotolerant and total coliforms. The other part of the fillet was packaged in an isothermal box with the ice sample for storage in a domestic refrigerator for eight hours. After this time, the same microbiological analyses were also carried out. It can be verified that the ice samples that were analyzed immediately after arriving at the laboratory did not present microbiological contamination. However, fillet samples had similar rates of bacterial contamination before and after storage. The ice that was used for the preparation of the fillets presented a quantity of mesophilic and psychrophilous heterotrophic bacteria similar to fillets.
\end{abstract}

Keywords: eterotrophic bacteria; coliformes; psychrotrophic.

\section{Introdução}

O Brasil possui aproximadamente $12 \%$ de toda água doce do planeta, $8.500 \mathrm{~km}$ de costa marítima e condições ambientais favoráveis para despontar como um dos maiores produtores de 
pescados do mundo (BRASIL, 2014). A produção de tilápias destaca-se como a maior espécie cultivada em território nacional, responsável por $45,4 \%$ da produção total, com 219 mil toneladas no período de janeiro a dezembro de 2015 (IBGE, 2015). É a espécie mais cultivada no Nordeste e neste mesmo ano, a região foi responsável por $24,1 \%$ da produção do país, com a atividade fortemente concentrada no estado do Ceará (Vidal, 2016).

A qualidade do pescado envolve sua composição intrínseca, fatores extrínsecos, nível de deterioração e suas características sensoriais. Para os consumidores as feira-livres e os mercados públicos são os melhores pontos de venda pela facilidade de escolha, compra e preços mais baixos (Mangas et al., 2016). A comercialização de pescados em mercado públicos e feiras livres é uma problemática recorrente, pois o pescado fica exposto nas barracas sem refrigeração adequada, sem proteção contra insetos, poeira, além da falta de higiene pessoal, equipamentos, utensílios e superfícies que entram em contato com o alimento (Barreto et al., 2012). Os peixes comercializados frescos devem estar submersos ao gelo, dificultando qualquer proliferação de microorganismos que podem vir a causar danos ao consumidor e acarretarem sérios problemas à saúde pública (Holanda et al., 2013).

Usualmente, os peixes em natureza podem ser comercializados inteiros, em postas ou filetados, conservado em gelo dentro de caixas isotérmicas (Perussatto et al., 2012) em mercados públicos ou feiras livres dos municípios (Holanda et al., 2013). De acordo com o Regulamento da Inspeção Industrial Sanitária de Produtos de Origem Animal (RIISPOA) pescado fresco é definido como "aquele que não foi submetido a qualquer processo de conservação, a não ser pela ação do gelo ou por meio de métodos de conservação de efeito similar, mantido em temperaturas próximas à do gelo fundente, com exceção daqueles comercializados vivos" (BRASIL, 2017a). E o acondicionamento correto é imprescindível para manter a qualidade do produto desde a captura, processamento até a comercialização (Alvez e Teófilo, 2016).

O gelo utilizado na conservação de alimento deve ser preparado com água potável e que atenda os parâmetros microbiológicos para consumo humano predito na RDC $\mathrm{n}^{\circ} 274$ de 22 de setembro de 2005 que aprova o regulamento técnico para águas envasadas e gelo (BRASIL, 2005). O gelo deve ser preparado a partir de água cujos parâmetros microbiológicos, químicos e radioativos atendam a norma de qualidade da água para consumo humana previsto na PRC $\mathrm{n}^{\circ} 5$ de 28 de setembro de 2017, anexo XX comunica que deve ter ausência de Escherichia coli em $100 \mathrm{~mL}$ da amostra na saída da estação e tratamento e na rede de distribuição (BRASIL, 2017b).

Prosenewicz e Lippi (2012) ressaltaram que a exposição ao ar livre dos peixes influência diretamente na qualidade do produto, pois há contato com partículas de poeira, insetos e outras sujidades inerentes ao ambiente de comercialização, além de refrigeração incorreta o que predispõem ao crescimento e multiplicação de micro-organismos indesejáveis.

O gelo possui função primordial de manter o frescor do peixe, apesar de não constituir um meio de cultivo pela ausência de nutrientes básicos para crescimento de micro-organismos, pode ser um importante veiculador de patógenos refletindo diretamente na qualidade final do produto, consistindo em um ponto crítico a ser controlado (Ferreira et al., 2014).

Em razão de o peixe possuir uma microbiota que pode sofrer alterações devido a contaminação direta, principalmente devido a manipulação e incorreta conservação, a comercialização de peixes e a qualidade do gelo utilizado na conservação em mercados públicos e/ou feira livres merecem atenção do consumidor no momento da compra igualmente para os órgãos fiscalizadores, com finalidade de reduzir a comercialização de produtos que possam vir a causar danos à saúde da população (Adedeji et al., 2012).

Diante do exposto, objetivou-se analisar a qualidade microbiológica do filé de tilápia (Oreochromis niloticus) e do gelo, e avaliar a interação de contaminação entre as partes analisadas.

\section{Material e Métodos}

As amostras de tilápias foram adquiridas no Mercado do Peixe, localizado em Teresina. As amostras coletadas apresentavam peso médio de $800 \mathrm{~g}$. A cada coleta de amostra de peixe, gelo era coletado diretamente da fábrica, localizada dentro do mercado, na qual era obtido através do trituramento da barra e usado como gelo controle de todas as amostras de filés de tilápias, acondionadas em caixas isotérmicas de primeiro uso protegidas internamente com sacos estéreis. 
Após as coletas, as tilápias foram transportadas em caixas isotérmicas para o Setor de Processamento de Pescado, do Núcleo de Estudos Pesquisas e Processamentos de Alimentos (NUEPPA), do Centro de Ciências Agrárias (CCA), da Universidade Federal do Piauí (UFPI), onde foram filetados em mesa de inox previamente desinfetadas com álcool 70\%, com facas de inox próprias para filetagem de pescados esterilizadas no calor úmido a uma temperatura de $85 \%$ aferida constantemente, uso de luvas estéreis para cada amostra filetada.

O filé do lado esquerdo era dividido em duas partes iguais. Uma porção (filé controle) era inserida individualmente em sacos plásticos estéreis identificados e posteriormente acondicionada em caixa isotérmica com gelo reciclável para manter a conservação. A outra porção (filé teste) era acondicionada em caixas isotérmicas individuais protegidas internamente com sacos plásticos estéreis e conservada no gelo (gelo controle) de forma que este cobrisse totalmente o filé de peixe.

As seguintes análises microbiológicas foram realizadas imediatamente no filé controle: enumeração de coliformes termotolerantes e totais, contagem de bactérias heterotróficas mesófilas e psicrotróficas. As caixas isotérmicas com as porções filé teste e gelo teste foram armazenadas por oito horas, período este referente ao tempo médio que o pescado é comercializado todos os dias no Mercado do Peixe de Teresina. Decorrido esse tempo também foram realizadas as mesmas análises microbiológicas do filé controle.

Os testes microbiológicos compreenderam as análises de coliformes totais e termotolerantes pela técnica do número mais provável (NMP/g), utilizando-se caldo Lauryl Sulphate Broth e incubado à $36^{\circ} \mathrm{C} \pm 1,0$ por $48 \mathrm{~h}$. Os tubos com resultados positivos foram repicados com alça de platina para tubos com caldo EC Broth e Verde Brilhante, em seguida incubados em banho-maria a $45,5^{\circ} \mathrm{C}$ por 24 horas e $37^{\circ} \mathrm{C}$ por 48 horas, respectivamente. Posteriormente foi realizada a leitura dos tubos positivos e os resultados expressos em NMP (Kornacki e Johnson, 2015).

Contagem padrão de bactérias heterotróficas mesófilas e psicrotróficas usando-se a técnica de plaqueamento em profundidade (pour-plate), com uso de Ágar Padrão para Contagem (PCA) em placas estéreis incubadas a $36^{\circ} \mathrm{C} \pm 1,0$ por $48 \mathrm{~h}$ e $7^{\circ} \mathrm{C}$ por 10 dias, respectivamente. $\mathrm{O}$ resultado foi expresso em unidades formadoras de colônias por grama de amostra (UFC/g). Todas as análises foram realizadas em duplicata (Silva et al., 2010; Elliot et al., 2015).

A análise estatística seguiu em um delineamento inteiramente casualizado em esquema fatorial com quatro pontos de coleta, duas amostras por ponto de coleta e três repetições, totalizando 24 amostras. Os dados obtidos das contagens microbiológicas foram transformados em $\log _{10}{ }^{(x+1)}$ e submetidos à análise de variância e comparação de médias pelo SNK considerando-se um nível de 5\% de significância, analisados através do software Sigma Stat 3,5.

\section{Resultados}

Com base nos resultados para Contagem de Bactérias Heterotróficas Mesófilas (CBHM) representado na Tabela 1, pode se observar que não houve diferença significativa $(\mathrm{p}>0,05)$ entre as contagens de filés controle (antes da estocagem) e filés teste (após estocagem). Para contagem de bactérias heterotróficas psicrotróficas não houve diferença significativa $(p>0,05)$ entre as contagens de filés controle e filés testes.

Tabela 1. Média e desvio padrão da contagem de bactérias heterotróficas mesófilas e psicrotróficas em amostras de filés de tilápias provenientes do mercado do peixe de Teresina, PI.

\begin{tabular}{ccc}
\hline Amostras & Bactérias Mesófilas & Bactérias Psicrotróficas \\
\hline Filé controle & $2,99^{\mathrm{a}} \pm 0,56$ & $3,65^{\mathrm{a}} \pm 0,72$ \\
Filé teste & $2,71^{\mathrm{a}} \pm 0,68$ & $3,87^{\mathrm{a}} \pm 0,65$
\end{tabular}

Letras minúsculas representam comparação na mesma linha. Resultados em médias \pm Desvio Padrão UFC/g em $\log 10^{(\mathrm{x}+1)}(\mathrm{P}>$ $0,05)$.

De acordo com a Tabela 2 houve diferença significativa entre a contagem de bactérias heterotróficas mesófilas e psicrotróficas do gelo teste e do gelo controle, confirmando assim que houve uma maior contaminação do gelo após a estocagem. 
Tabela 2. Média e desvio padrão da contagem de bactérias heterotróficas mesófilas e psicrotróficas em amostras gelo provenientes do mercado do peixe de Teresina, PI.

\begin{tabular}{lcc}
\hline Amostras & Bactérias Mesófilas & Bactérias Psicrotróficas \\
\hline Gelo controle & $0,53^{\mathrm{b}} \pm 0,77$ & $0,53^{\mathrm{b}} \pm 0,77$ \\
Gelo teste & $2,67^{\mathrm{a}} \pm 0,45$ & $2,67^{\mathrm{a}} \pm 0,45$
\end{tabular}

Letras minúsculas representam comparação na mesma linha. Resultados em médias \pm Desvio Padrão UFC/g em log $10^{(\mathrm{x}+1)}(\mathrm{P}<$ $0,05)$.

Conforme disposto na Tabela 3, houve diferença significativa $(\mathrm{p}<0,05)$ para contagem de coliformes totais entre as amostras de gelo controle e teste. Este último apresentou-se com maior contaminação comparada ao primeiro, enquanto que as amostras de filés não apresentaram diferença significativa quando analisada antes (filé controle) e após a estocagem (filé teste). Os resultados podem apontar que houve contaminação das amostras de gelo teste durante a execução das análises.

Não houve diferença significativa entre as médias de coliforme termotolerantes, assim as amostras de filés e de gelo permaneceram inalteradas após estocagem, não havendo interação entre os fatores analisados.

Tabela 3. Média e desvio padrão de coliformes totais em amostras de filé de peixe (controle e teste) e gelo (controle e teste) provenientes do mercado do peixe de Teresina, PI.

\begin{tabular}{ccccccccc}
\hline & \multicolumn{9}{c}{ Coliformes Totais } \\
Repetições & \multicolumn{2}{c}{ Gelo Teste } & \multicolumn{2}{c}{ Gelo Controle } & \multicolumn{2}{c}{ Peixe Teste } & \multicolumn{2}{c}{ Peixe Controle } \\
\cline { 2 - 9 } 1 & $0,65^{\mathrm{a}}$ & $\pm 0,53$ & $0,00^{\mathrm{b}}$ & $\pm 0,00$ & $0,00^{\mathrm{b}}$ & $\pm 0,00$ & $0,00^{\mathrm{b}}$ & $\pm 0,00$ \\
2 & $1,12^{\mathrm{a}}$ & $\pm 0,18$ & $0,00^{\mathrm{b}}$ & $\pm 0,00$ & $0,00^{\mathrm{b}}$ & $\pm 0,00$ & $0,00^{\mathrm{b}}$ & $\pm 0,00$ \\
3 & $0,72^{\mathrm{a}}$ & $\pm 0,64$ & $0,00^{\mathrm{b}}$ & $\pm 0,00$ & $0,00^{\mathrm{b}}$ & $\pm 0,00$ & $0,00^{\mathrm{b}}$ & $\pm 0,00$ \\
\hline
\end{tabular}

Letras minúsculas representam comparação na mesma linha. Resultados em médias \pm Desvio Padrão $(\mathrm{P}<0,05)$.

\section{Discussão}

A legislação brasileira, RDC no 12 de 02 de janeiro de 2001 (BRASIL, 2001), não determina os limites de tolerância para mesófilos, psicrotróficos, coliformes totais e coliformes termotolerantes em pescado in natura resfriados não consumido cru, assim os valores encontrados não podem ser comparados a um padrão, porém Soares et al. (2011) ressaltaram a importância da pesquisa desses micro-organismos indicando as condições higiênico-sanitárias do pescado.

Britto et al. (2007) analisaram filés de peixe no dia da compra e obtiveram resultados de 4,4 $\log ^{10} \mathrm{UFCg}^{-1}$ para bactérias heterotróficas mesófilas, mas ao analisarem em intervalos de dias diferentes verificaram que o armazenamento em gelo contribui para redução na contagem de bactérias mesófilas e ao comparar os resultados com este estudo observou-se que as contagens para bactérias mesófilas foram inferiores, de 2,99 $\log ^{10}$ $\mathrm{UFCg}^{-1}$.

Soares et al. (2011) ao analisarem filé de tilápias em gelo escama detectaram Contagem de Bactérias Heterotróficas Mesófilas (CBHM) de 2,90 $\log ^{10} \mathrm{UFCg}^{-1}$, valores esses semelhantes ao encontrados nesse trabalho, porém ao analisarem os filés com três dias de estocagem notou-se aumento considerável na CBHM, os resultados encontrados no presente trabalho demonstraram que a estocagem do filé por oito horas não contribui para o aumento da contagem de bactérias mesófilas.

Já para bactérias psicrotróficas, Lanzarin et al. (2011) ressaltaram a importância de uma revisão na legislação brasileira para que sejam inseridos limites máximos permitidos nesses alimentos. Soares et al. (2011) encontraram em seus estudos limites de 0 a $9,1 \log 10 \mathrm{UFCg}^{-1}$ afirmando que concentrações altas desses micro-organismos reduzem a qualidade do produto e podem ser um potencial risco a saúde dos consumidores.

Leitão et al. (1997) detectaram que há uma lenta multiplicação de bactérias psicrotróficas quando armazenados $5^{\circ} \mathrm{C}$, compatíveis com os dados obtidos nesse trabalho que após oito horas de armazenamento a Contagem de Bactérias Heterotróficas Psicrotróficas (CBHP) teve um aumento em relação a contagem realizada antes da 
estocagem, porém afirmam que foi possível detectar limites que pudessem causar deterioração somente após estocagem depois de 14 dias.

Scherer et al. (2004) afirmaram que as bactérias psicrotróficas aumentam significativamente ao longo da armazenagem e que só a utilização do gelo clorado é capaz de reduzir a contagem e aumentar a vida útil em três dias.

International Commissionon Microbiological Specifications for Foods (ICMSF, 1986) permite contagem máximas para contagem de bactérias mesófilas e psicrotróficas de $10^{7} \mathrm{UFCg}^{-1}$, mostrando que os filés de peixes estavam aptos para consumo mesmo após a estocagem.

A Portaria de Consolidação $\mathrm{N}^{\circ}$ 5, de 28 de setembro de 2017, em seu anexo XX, trata do controle e da vigilância da qualidade da água para consumo humano e seu padrão de potabilidade, e embora exista esta legislação específica, ainda é utilizada água não potável para fabricação de gelo, tornando-se um risco iminente para o consumidor, supondo-se que a qualidade microbiológica do gelo influência diretamente na qualidade e duração da vida de prateleira do produto, e que o gelo contaminado pode vir a contaminar o peixe após armazenagem.

Este trabalho confirmou, após analises dos resultados, que a contagem de bactérias heterotróficas mesófilas e psicrotróficas do filé de tilápias influenciam diretamente na qualidade final do gelo concordando com os dados obtidos por Pimentel e Panetta (2003) que afirmaram que o gelo cumpre a função de conservação e não influência na contaminação do pescado. Entretanto verificou-se objeção ao que Giampietro e RezendeLago (2009), Baldin et al. (2016) presumiram em seus trabalhos que o gelo pode ser uma fonte direta de contaminação do pescado.

As amostras de filé não apresentaram contaminação por coliformes totais e termotolerantes antes da estocagem. Soares et al. (2011) ao estudarem peixes congelados verificaram que as amostras estavam contaminadas por coliformes totais e coliformes termotolerantes indicando erros nos procedimentos de manipulação e/ou processamento do pescado.

Ainda em análise ao trabalho de Soares et al. (2011) pode-se perceber que a cadeia de frio é de suma importância para conservar as caraterísticas iniciais do pescado, mas que mesmo em temperaturas de congelamento não é possível barrar a contaminação do pescado apenas retardando o crescimento e multiplicação bacteriana.

A legislação brasileira recomenda que tenha ausência de coliformes totais e Escherichia coli em $100 \mathrm{~mL}$ de água (BRASIL, 2017b). Desta forma, as amostras de gelo encontram-se em condições para consumo humano em contradição aos resultados obtidos por Dorta et al. (2011) em que todas as amostras de gelo comercializadas em fabricas de gelo do município de Teresina foram constatados coliformes totais.

Ferreira et al. (2014) analisaram amostras de gelo no Maranhão e constataram que $75 \%$ das amostras estavam contaminadas por coliformes totais e termotolerantes, porém Baldin et al. (2016) encontraram em $22,2 \%$ coliformes totais e em 9,5\% coliformes termotolerantes e atribuíram o maior número de amostras advinda de propriedades onde o uso da água era de poço artesiano e ineficiência da cloração da água.

\section{Conclusão}

A qualidade microbiológica do gelo e dos filés de tilápias analisados, está de acordo com os padrões requeridos pela legislação brasileira.

Os filés de peixes contribuíram para a contaminação do gelo após a estocagem, mas tal fato não prejudicou a sua qualidade microbiológica, estando de acordo com a padronização da legislação específica.

\section{Agradecimentos}

Ao Conselho Nacional de Desenvolvimento Científico e Tecnológico (CNPq) pela concessão da bolsa de mestrado.

\section{Conflito de interesse}

Os autores declaram não existir conflito de interesse.

\section{Referências}

Adedeji, O.B.; Okerentugba, P.O.; InnocentAdiele, H.C.; Okonko, I.O. Benefits, public health hazards and risks associated with fish consumption. New York Science Journal, 5(9):33-61, 2012.

Alves, G.L.; Teófilo, T.S. Aspectos higiênicossanitários de estabelecimentos de comercialização de pescados no "Mercado do Peixe" em São Luís - MA. Revista Científica de Medicina Veterinária, (26): 1-8, 2016.

Baldin, J.C.; Borges, L.A.; Gatti Júnior, P.; Michelin, 
E.C.; Rossi Junior, O.D. Qualidade microbiológica do gelo utilizado na conservação de pescado. Global Science Technology, 9(2): 74-78, 2016.

Barreto, N.S.E.; Moura, F.C.M.; Teixeira, J.A. Assim, D.A. Miranda, P.C. Avaliação das condições higiênico sanitárias do pescado comercializado no Município de Cruz Almas, Bahia. Revista Caatinga, 25(3): 86-95, 2012.

BRASIL. Ministério da Agricultura, Pecuária e Abastecimento. Decreto $\mathrm{n}^{0} 9013$ de 29 de março de 2017. Regulamento da inspeção industrial e sanitária de produtos de origem animal. Diário oficial da República Federativa do Brasil. Brasília, DF, de 29 de março de $2017 \mathrm{a}$.

BRASIL. Ministério da Pesca e Aquicultura. A pesca no Brasil. Brasília, DF, 2014.

BRASIL. Ministério da Saúde. Agência Nacional de Vigilância Sanitária. RDC n⿳0 12, de 02 de janeiro de 2001. Aprova o Regulamento sobre padrões microbiológicos para alimentos e seus anexos I e II. Diário oficial da República Federativa do Brasil, Brasília, DF, $n^{\circ} 7$ p. 45-53, de 10 de janeiro de 2001. Seção 1.

BRASIL. Ministério da Saúde. Agência Nacional de Vigilância Sanitária. Resolução RDC $\mathbf{n}^{0}$ 274 de 22 de setembro de 2005. Aprova o Regulamento técnico para águas envasadas e gelo. Diário Oficial da União; Poder Executivo, de 23 de setembro de 2005.

BRASIL. Ministério da Saúde. Portaria de consolidação $\mathbf{n}^{0} 5$, de 28 de setembro de 2017. Consolidação das normas sobre as ações e os serviços de saúde do Sistema Único de Saúde. Diário Oficial da República Federativa do Brasil, Brasília, DF, $\mathrm{n}^{\circ}$ 190, 03 de outubro de 2017b.

Britto, E.N.; Lessi, E.; Cardoso, A.L.; Falcão, P.T.; Santos, J.G. Bacteriological deterioration of jaraqui Semaprochilodus spp. captured in the state of Amazon, and conserved in ice Acta Amazonica, 37(3): 457-464, 2007.

Dorta, V.F.; Muratori, M.C.S.; Almeida, C.K.S; Silva, R.M.; Cardoso Filho, F.C. Condições higiênico-sanitárias do gelo utilizado para conservação do pescado nos mercados de Teresina, PI. Higiene Alimentar, 25(196/197): 124-128, 2011.

Elliot, T.; Ryser, E.T.; Schuman, J.D. Shuman. Mesophilic aerobic plate count. In: Salfinger, Y.; Tortorello, M.L. Compendium of methods for the microbiological examination of foods. 5 ed. Compendium of methods for the microbiological examination of foods. 5. ed. Washington: American Public Health Association, 2015. Cap. 8, p. 47-68.

Ferreira, E.M.; Lopes, I.S.; Pereira, D.M.; Rodrigues, L.C.; Costa, F.N. Qualidade microbiológica do peixe serra (Scomberomerus brasiliensis) e do gelo utilizado na sua conservação. Arquivo do Instituto Biológico, 81(1): 49-54, 2014.

Giampietro, A.; Rezende-Lago, N.C.M. Qualidade do gelo utilizado na conserva de gelo fresco. Arquivo do Instituto Biológico, 76(3): 505508, 2009.

Holanda, M.F.A.; Silva, M.A.M.P.; Pinto, L.I.F.; Brandão, T.M.; Silva, R.A. Avaliação das condições higiênico-sanitárias das feiras livres de comercialização de peixe na cidade de Caxias - MA. Acta Tecnológica, 8(2): 30-35, 2013.

IBGE. Instituto Brasileiro de Geografia e Estatística. 2015. Disponível em: <http://www.ibge.gov.br/home/>. Acesso em: 15 fev. 2017.

ICMSF - International Commission on Microbiological Specifications for Foods. Sampling for microbiological analysis: principles and specific applications. $2^{\text {nd }} . e d$. London: Blackwell Scientific Publications, 1986.131p.

Kornacki, J.L.; Johnson, J.L. Enterobacteriaceae, coliforms, and Escherichia coli as quality and safety indicators. In: Downes, F.P.; Ito, K. Compendium of methods for the microbiological examination of foods. $5^{\text {a }}$ ed. Washington: American Public Health Association, 2015. Cap. 9, p. 69-82.

Lanzarin, M.; Almeida Filho, E.S.; Ritter, J.A.; Melo, C.A. Corrêa, G.S.S. Ignácio, C.M.S. Ocorrência de Aeromonas sp. e microrganismos psicrotróficos e estimativa do prazo de validade comercial de filé de pintado (Pseudoplatystoma coruscans) mantidos sob refrigeração. Arquivo Brasileiro de Medicina Veterinária e Zootecnia, 63(6): 1541-1546, 2011.

Leitão, M.F.F.; Rios, D.P.F.A.; Guimarães, J.G.L.; Baldini, V.L.S.; Pinto, C.S.R.M. Alterações químicas e microbiológicas em pacu (Piaractus mesopotamicus) armazenado sob refrigeração a $5^{\circ} \mathrm{C}$. Ciência e Tecnologia de Alimentos, 17(2): 160-166, 1997. 
Mangas, F.P.; Rabello, F.K.; Santos, M.A.S.; Martins, C.M. Caracterização do perfil dos consumidores de peixe no munícipio de Belém, estado do Pará, Brasil. Revista em Agronegócio e Meio Ambiente, 9(4); 839$857,2016$.

Perussatto, A.; Camara, D.; Miritz, L. D. Coronel, D.A. Cadeia produtiva dos peixes comercializados na feira municipal do peixe vivo de Palmeira das Missões/ RS: uma estratégia de desenvolvimento. Diálogo, 21(21): 207-224, 2012.

Pimentel, L.P.S.; Panetta, J.C. Condições higiênicas do gelo utilizado na conservação de pescado comercializado em supermercados da grande São Paulo. Parte I, resultados microbiológicos. Revista Higiene Alimentar, 17(106): 56-63, 2003.

Prosenewicz, I.; Lippi, U. G. Acesso aos serviços de saúde, condições de saúde e exposição aos fatores de risco: percepção dos pescadores ribeirinhos do Rio Machado de Ji-Paraná, RO. Saúde e Sociedade, 21(1): 219-231, 2012.

Scherer, R.; Daniel, A.P.; Augusti, P.R.; Lazzari, D.; Lima, R.L.; Fries, L.L.M.; Randuz Neto, J.; Emanuelli, T. Efeito do gelo clorado sobre parâmetros químicos e microbiológicos da carne de carpa capim (Ctenopharyngodon idella). Revista Ciência e Tecnologia de Alimentos, 24(4): 680-684, 2004.

Silva, N.; Junqueira, V.C.A.; Silveira, N.F.A. Manual de métodos de análise microbiológica de alimentos e água. $4^{\mathrm{a}} \mathrm{ed}$. São Paulo: Livraria Varela, 2010. 624 p.

Soares, V.M.; Pereira, J.G.; Izidorio, T.B.; Martins, O.A.; Pinto, J.P.A.N.; Biondi, G.F. Qualidade Microbiológica de Filés de Peixe Congelados Distribuídos na Cidade de Botucatu - SP. UNOPAR Científica Ciências Biológicas e Saúde, 13(2): 85-88, 2011.

Vidal, M.F. Panorama da piscicultura no nordeste. Caderno Setorial ETENE. 1(3): , 2016. 